\title{
Asymmetry and Incoherence: A Reply to Cyr
}

\author{
Jens Johansson ${ }^{1}$
}

Received: 3 July 2016/Accepted: 12 July 2016/Published online: 17 August 2016

(C) The Author(s) 2016. This article is published with open access at Springerlink.com

\begin{abstract}
In defense of the Deprivation Approach to the badness of death against the Lucretian objection that death is relevantly similar to prenatal nonexistence, John Martin Fischer and Anthony L. Brueckner have suggested that whereas death deprives us of things that it is rational for us to care about, prenatal nonexistence does not. I have argued that this suggestion, even if correct, does not make for a successful defense of the Deprivation Approach against the Lucretian objection. My criticism involved a thought experiment in which a person avoids being tortured. Recently, Taylor Cyr has defended Fischer and Brueckner's approach, arguing that my thought experiment is incoherent. In this response, I question both the truth and relevance of Cyr's incoherence claim.
\end{abstract}

Keywords Evil of death · Deprivation approach $\cdot$ Prenatal non-existence $\cdot$ John Martin Fischer · Anthony L. Brueckner · Taylor Cyr

\section{Introduction}

In those cases where death is bad for the person who dies, why is it bad for him? That is, what makes his death bad for him? According to the "Deprivation Approach," in its standard form, the answer to this question is that the person would have been on balance intrinsically better off if his death had not occurred. (Bradley 2009: 50; Broome 1993; Feldman 1992: 138) This view, while attractive, faces a number of challenges, one of the most important of which is the Lucretian "symmetry" objection. (Lucretius 1940: 134) If the explanation of death's badness is the one provided by the Deprivation Approach, then it seems that, in many cases, the person's prenatal nonexistence-the fact that he does not come into existence

Jens Johansson

jens.johansson@filosofi.uu.se

1 Department of Philosophy, Uppsala University, Box 627, 75126 Uppsala, Sweden 
substantially earlier and thereby gets a substantially longer life-must be bad for him as well. For, in many cases, if it were not for the person's prenatal nonexistence, then he would have been on balance intrinsically better off. However, even in such cases, the person's prenatal nonexistence does not seem to be a bad thing for him, as indicated by the fact that no one seems to be even mildly upset by it. Thus, the argument continues, if death is an evil, it cannot be for the reason offered by the Deprivation Approach. (Those who, like Lucretius, are followers of Epicurus might want to add that, if death were an evil, it would be for the reason offered by the Deprivation Approach; therefore, they might conclude, death is no evil.)

In "Past and Future Non-Existence" (Johansson 2013), I evaluated some proposed responses to the symmetry objection. One of these was John Martin Fischer and Anthony L. Brueckner's proposal, according to which there is a crucial asymmetry between death and prenatal nonexistence. (e.g., Brueckner and Fischer 1986; Fischer and Brueckner 2013) The crucial asymmetry, Fischer and Brueckner argue, lies in the fact that death deprives us of having pleasant experiences in the future, which it is rational for us to care about, whereas prenatal nonexistence only deprives us of having had pleasant experiences in the past, which it is not rational for us to care about. I argued that this does not make for a successful defense of the Deprivation Approach against the symmetry objection, since it is irrelevant whether it is actually rational for us to care about the experiences of which our death, or prenatal nonexistence, deprives us. In support of this charge, I provided a thought experiment involving torture.

Taylor Cyr's recent article, "Rationally Not Caring about Torture" (Cyr 2014) is a defense of Fischer and Brueckner's approach against this criticism. ${ }^{1}$ Cyr's main charge is that my thought experiment is incoherent. Duncan Purves has replied on my behalf, arguing that, ironically, Cyr's argument renders Fischer and Brueckner's approach incoherent. (Purves 2015) Cyr has responded to this criticism. (Cyr 2015) Whether or not Cyr's response to Purves is correct, however, his defense of Fischer and Brueckner against my criticism strikes me as unpersuasive. In this paper, I seek to show that my thought experiment is not incoherent, and that, even if it were, this would not undermine my criticism of Fischer and Brueckner's approach.

\section{Cyr's Incoherence Charge}

To understand Cyr's objection, let us first recapitulate Fischer and Brueckner's view and my criticism. Fischer and Brueckner have formulated several different principles in order to capture their main idea, but the one that Cyr focuses on is the following:

$\mathrm{BF}^{*}(\mathrm{dd})^{*}$ : When death is bad for an individual $X$, it is bad for $X$ because it is rational for $X$ to care about having pleasant experiences after $t$ (where $t$ is the time of his death), and his death deprives him of having pleasant experiences

\footnotetext{
1 For Fischer and Brueckner's own responses, see Fischer and Brueckner (2014a, b, c); I reply in Johansson (2014a, b). See also Deng (2015) and Feldman (2013).
} 
after $t$ (whereas prenatal non-existence is not bad for a person because, even though it deprives him of having had pleasant experiences before $t^{*}$ (where $t^{*}$ is the time at which he came into existence), it is not rational for him to care about having had pleasant experiences before $t^{*}$ ). (Fischer and Brueckner 2014a: 4)

I noted that principles along these lines do not save the standard version of the Deprivation Approach from the Lucretian problem. (Johansson 2013: 62, 63n.) For as mentioned above, according to the standard version of the Deprivation Approach, a person's death is bad for him because he would have been on balance intrinsically better off if his death had not taken place. And whether this condition is satisfied or not does not depend on whether it is actually rational for the person to care about the pleasant experiences of which his death deprives him. It is at least arguable that how intrinsically well off the person is in the closest possible world in which his death does not occur is in part determined by the extent to which it is rational for him in that world to care about the additional pleasant experiences he receives in that world. However, how intrinsically well off he is in that world can hardly be determined, even in part, by the extent to which it is rational for him in some other possible world to care about those experiences (such as the actual world, in which he does not have them).

I also noted, however, that maybe Fischer and Brueckner are happy to reject the standard version of the Deprivation Approach. The question, then, is whether their alternative version is a plausible one. ${ }^{2}$ I claimed that it is not. If an event is bad for someone, this is not because it deprives him of pleasant experiences that it is actually rational for him to care about. In support of this judgment, I argued that the analogous thing holds for pain and goodness. I wrote:

[C]ompare with pain and goodness: even if, for some reason, it is not actually rational for a person to care about a painful torture, it is still good for her to avoid the torture, at least provided that, if she had been tortured, it would have been rational for her to care about it and she would have been on balance worse off. Surely the analogous thing holds for pleasure and badness. (Johansson 2013: 63n.)

However, Cyr objects that this thought experiment is incoherent. My argument, he argues, requires both of the following claims to be true in the scenario in question (where "Susan" is his name for the protagonist of the story):

(A) It is not actually rational for Susan to care about whether or not she is painfully tortured.

(B) If Susan were to be tortured, it would be rational for her to care about painful torture.

\footnotetext{
${ }^{2} \mathrm{Cyr}$ is apparently reluctant to call Fischer and Brueckner's version of the Deprivation Approach an "alternative": "[I]t should be noted that Fischer and Brueckner take this so-called 'alternative' just to be their view." (Cyr 2014: 335) I agree with Cyr that Fischer and Brueckner's view is not an alternative to itself; my claim was only that it is an alternative to the standard version of the Deprivation Approach.
} 
According to Cyr, however, "these claims are mutually exclusive" (Cyr 2014: 337). He argues as follows:

If (A) were true, it would have to be for the reason that Susan is so constituted that she would not "feel" or "be bothered by" pain if she were subjected to it, or for some very similar reason. According to (B), though, it would also have to be the case that it would be rational for Susan to care about being tortured if it were to happen to her. But it would not be rational to care about it if she could not "feel" pain (or "be bothered by" pain, or something of this sort), as we have stipulated in order to explain how (A) might be true. So, to summarize, any reason that we can stipulate to make (A) true ... is going to falsify (B) by making it the case that it would not be rational for her to care about the painful torture. Conversely, if (B) is true, and thus it is rational for her to care about painful torture, (A) cannot also be true, for it is rational for her to care about painful torture. (Cyr 2014: 337)

In short, according to Cyr, if we fill in the details of the case appropriately, we might render (A) true, but then we will automatically also render (B) false. So, in his view, my criticism of Fischer and Brueckner's approach relies on an incoherent example, and is thus a failure.

\section{Response to $\mathrm{Cyr}$}

First of all I should perhaps point out that (B) might not be strictly speaking essential for my purposes. The crucial matter, as I see it, is that Susan would have been on balance intrinsically worse off if she were subjected to torture: that seems to be clearly sufficient to make it good for her to avoid the torture. I acknowledge, however, that it would be problematic to say that that condition is satisfied while (B) is false (for instance, as noted above, it is at least arguable that how intrinsically well off Susan is in a possible world is in part determined by whether it is rational for her in that world to care about the experiences she has in that world), and so I will not explore the option of dropping (B).

Is Cyr right that the thought experiment is incoherent? As we just saw, Cyr thinks that if (A) is true, then this must be because Susan would not "feel" or "be bothered by" pain even if she were subjected to it, or for some closely related reason. But even supposing that Cyr is right that any reason of that sort would render (B) false, it seems to me that (A) could be true for other sorts of reasons, which would not render (B) false. Consider the view that it is rational for a person to care about painful torture if and only if that painful torture is at least fairly likely to take place. It does not matter here whether we understand likelihood in objective or subjective terms: in either case, this view can hardly be incoherent (whether or not it is true). Now, suppose that it is not actually fairly likely that Susan will be tortured, although, if she were to be tortured, then the torture would be likely to happen. Then the view at hand renders both (A) and (B) true. Because the view and our assumptions about the likelihood of the torture jointly entail both (A) and (B), and 
are not themselves mutually exclusive, (A) and (B) are not mutually exclusive, contrary to Cyr's contention.

So, the thought experiment is not incoherent. Suppose for the sake of argument, however, that Cyr is right that it is. How would this affect my criticism of Fischer and Brueckner's approach? As I see it, it would not undermine this criticism. Of course, incoherence is often a vice: for instance, any incoherent theory is bound to be false, and any argument with incoherent premises is bound to be unsound. However, it is often perfectly legitimate to ask us to suppose or pretend that something incoherent is the case in order to make an important point. Most obviously, this holds for reductio ad absurdum arguments against incoherent claims. ("Suppose you are right that some triangles are squares. Then something has both exactly three sides and more than exactly three sides, which is absurd.") But it can also be legitimate to make an incoherent supposition in order to reveal or highlight that some proposed explanation of some fact appeals to an irrelevant factor. The irrelevance of the factor in question can usefully be brought out by supposing that the factor is absent from a certain situation, whether or not this supposition makes the story incoherent. For example, imagine that someone suggests that when death is bad for a person, it is bad for him because the following conjunctive fact holds: The person's death deprives him of having pleasant experiences after $t$ (the time of his death) and if God existed, then God would believe that the death deprives the person of having pleasant experiences after $t$. We protest, naturally enough, that the second conjunct is not plausibly part of the explanation. To bring this out, we tell our interlocutor: "Suppose that the person's death deprives him of having pleasant experiences after $t$, but that, for whatever reason, it is false that if God existed, then God would believe that the death deprives the person of having pleasant experiences after $t$. Surely if the person's death is bad for him in a case where both conjuncts of your proposed explanans are true, then it is also bad for him in this case." Arguably, it is a conceptual truth that God, if he existed, would be omniscient; if so, our supposition is incoherent. Nevertheless, our thought experiment still seems to give us a good argument against the interlocutor's suggestion. The assumption that the allegedly relevant factor-the second conjunct, referring to God's beliefs-is absent from the case helps us see that the factor in fact does not do any explanatory work. Of course, in some circumstances the second conjunct might provide evidence that the person's death is bad for him. But what our supposition helps to bring out is that the second conjunct is not part of what explains death's badness; it is not part of what makes the person's death bad for him.

The torture case has a similar function. I think it is clear that the goodness for Susan of avoiding painful torture is entirely a matter of what this saves her fromnamely, a possible scenario in which the painful torture is making her on balance intrinsically worse off. The fact that avoiding torture saves her from being in that terrible scenario is enough to make it good for her. By contrast, its being rational for Susan in the actual world, in which she is not subjected to torture, to care about being subjected to torture is neither here nor there (just as it is neither here nor there whether she does care about torture in the actual world, or in any other world in which she is not subjected to torture). While in many circumstances that factor may provide evidence that avoiding torture is good for Susan, it is not plausibly part of 
what explains why avoiding torture is good for her: it is not part of what makes it good for her. Although I think all this is reasonably clear even without the supposition that this factor is absent from the situation, that supposition-that is, supposition (A) - is still a useful way of bringing out the factor's explanatory irrelevance. It helps us see that the factor is not doing any work in explaining the goodness for Susan of avoiding torture. And just as in the "God's beliefs" example above, the supposition serves this purpose whether or not it makes the thought experiment incoherent. ${ }^{3}$

At this point, however, some might want to object as follows: While the fact that the torture would have made Susan intrinsically worse off is admittedly enough for it to be good for her to avoid torture, it is nonetheless true that if it is, in addition, actually rational for Susan to care about being tortured, then this makes avoiding torture even better for her. Similarly, it may be suggested, while the fact that a person's death deprives him of a scenario in which he is on balance intrinsically better off is admittedly enough to make his death bad for him, it is nonetheless true that if it is, in addition, actually rational for him to care about the pleasant experiences of which his death deprives him, then this makes his death even worse for him. Thus, on this view, its actually being rational for the person to care about the experiences which a certain event prevents him from receiving does, after all, play a role in determining the event's value for the person. I do not personally find this view attractive. But in any case, it would not be a way of saving $\mathrm{BF}^{*}(\mathrm{dd})^{*}$. For recall that $\mathrm{BF}^{*}(\mathrm{dd})^{*}$ says, among other things, that the person's prenatal nonexistence is not bad for him because it is not rational for him to care about the pleasant experiences of which it deprives him. If, as the present suggestion says, making the person on balance intrinsically worse off is enough for being bad for him, then the person's prenatal nonexistence, which does make him on balance intrinsically worse off, is bad for him after all, contrary to $\mathrm{BF}^{*}(\mathrm{dd})^{*}$.

Open Access This article is distributed under the terms of the Creative Commons Attribution 4.0 International License (http://creativecommons.org/licenses/by/4.0/), which permits unrestricted use, distribution, and reproduction in any medium, provided you give appropriate credit to the original author(s) and the source, provide a link to the Creative Commons license, and indicate if changes were made.

\section{References}

Bradley, B. 2009. Well-being and death. Oxford: Oxford UP.

Broome, J. 1993. Goodness is reducible to betterness: The evil of death is the value of life. In The good and the economical: Ethical choices in economics and management, ed. P. Koslowski, and Y. Shionoya, 70-84. Berlin: Springer.

Brueckner, A.L. and J.M. Fischer 1986. Why is death bad? In Philosophical Studies 50: $213-223$. (Reprinted in The metaphysics of death, ed. J.M. Fischer, 221-229, Stanford: Stanford UP, 1993).

Cyr, T. (2014). Rationally not caring about torture: a reply to Johansson. The Journal of Ethics 18: $331-339$.

\footnotetext{
3 Perhaps the incoherence cannot be altogether obvious in order for the relevant supposition to serve this sort of purpose. However, the incoherence is not obvious in either of the two cases discussed here (indeed, as I explained above, I do not think that the torture case is incoherent).
} 
Cyr, T. (2015). Death's badness and time-relativity: a reply to Purves. The Journal of Ethics. doi:10.1007/ s10892-015-9200-y.

Deng, N. 2015. How A-theoretic deprivationists should respond to Lucretius. Journal of the American Philosophical Association 1: 417-432.

Feldman, F. 1992. Confrontations with the reaper. New York: Oxford UP.

Feldman, F. 2013. Brueckner and Fischer on the evil of death. Philosophical Studies 162: 309-317.

Fischer, J.M., and A.L. Brueckner. 2013. The evil of death and the Lucretian symmetry: a reply to Feldman. Philosophical Studies 163: 783-789.

Fischer, J.M., and A.L. Brueckner. 2014a. Prenatal and posthumous non-existence: a reply to Johansson. The Journal of Ethics 18: 1-9.

Fischer, J.M., and A.L. Brueckner. 2014b. Accommodating counterfactual attitudes: a further reply to Johansson. The Journal of Ethics 18: 19-21.

Fischer, J.M., and A.L. Brueckner. 2014c. The mirror-image argument: an additional reply to Johansson. The Journal of Ethics 18: 325-330.

Johansson, J. 2013. Past and future non-existence. The Journal of Ethics 17: 51-64.

Johansson, J. 2014a. Actual and counterfactual attitudes: reply to Brueckner and Fischer. The Journal of Ethics 18: 11-18.

Johansson, J. 2014b. More on the mirror: reply to Fischer and Brueckner. The Journal of Ethics 18: 341-351.

Lucretius 1940. On the nature of things. In The Stoic and Epicurean philosophers, ed. W.J. Oates, transl. H.A.J. Munro, 69-219. New York: The Modern Library.

Purves, D. 2015. Torture and incoherence: a reply to Cyr. The Journal of Ethics 19: 213-218. 